\title{
Evaluating the effect of interventions for strengthening non-physician anesthetists' education in Ethiopia: a pre- and post- evaluation study
}

Yohannes Molla Asemu ${ }^{1,6^{*}}$, Tegbar Yigzaw ${ }^{1}$, Firew Ayalew Desta ${ }^{1}$, Fedde Scheele ${ }^{2,3,4,5}$ and Thomas van den Akker ${ }^{6,7}$

\begin{abstract}
Background: Access to safe surgery has been recognized as an indispensable component of universal health coverage. A competent anesthesia workforce is a prerequisite for safe surgical care. In Ethiopia, non-physician anesthetists are the main anesthesia service providers. The Government of Ethiopia implemented a program intervention to improve the quality of non-physician anesthetists' education, which included faculty development, curricula strengthening, student support, educational resources, improved infrastructure and upgraded regulations. This study aimed to assess changes following the implementation of this program.

Methods: A pre-and post-evaluation design was employed to evaluate improvement in the quality of non-physician anesthetists' education. A 10-station objective structured clinical examination (OSCE) was administered to graduating class anesthetists of $2016(n=104)$ to assess changes in competence from a baseline study performed in 2013 ( $n=$ 122). Moreover, a self-administered questionnaire was used to collect data on students' perceptions of the learning environment.

Results: The overall competence score of 2016 graduates was significantly higher than the 2013 class (65.7\% vs. 61.5\%, mean score difference $=4.2,95 \% \mathrm{Cl}=1.24-7.22, p<0.05$ ). Although we found increases in competence scores for 6 out of 10 stations, the improvement was statistically significant for three tasks only (pre-operative assessment,

postoperative complication, and anesthesia machine check). Moreover, the competence score in neonatal resuscitation declined significantly from baseline (from 74.4 to $68.9 \%$, mean score difference $=-5.5,95 \% \mathrm{Cl}=-10.5$ to $-0.5, p<0.05$ ). Initial gender-based performance differences disappeared (66.3\% vs. $65.3 \%$, mean score difference $=-1.0,95 \% \mathrm{Cl}=$ $-6.11-3.9, p>0.05$ in favor of females), and female students scored better in some stations. Student perceptions of the learning environment improved significantly for almost all items, with the largest percentage point increase in the availability of instructors from 38.5 to $70.2 \%(\mathrm{OR}=3.76,95 \% \mathrm{Cl}=2.15-6.55, p<0.05)$.
\end{abstract}

\footnotetext{
* Correspondence: mollayo98@yahoo.com

'Jhpiego, An affiliate of Johns Hopkins University, Ethiopia country office, Addis Ababa, Ethiopia

${ }^{6}$ Athena Institute, Faculty of Science, Vrije Universiteit Amsterdam, Amsterdam, The Netherlands

Full list of author information is available at the end of the article
}

(c) The Author(s). 2021 Open Access This article is licensed under a Creative Commons Attribution 4.0 International License, which permits use, sharing, adaptation, distribution and reproduction in any medium or format, as long as you give appropriate credit to the original author(s) and the source, provide a link to the Creative Commons licence, and indicate if changes were made. The images or other third party material in this article are included in the article's Creative Commons. licence, unless indicated otherwise in a credit line to the material. If material is not included in the article's Creative Commons licence and your intended use is not permitted by statutory regulation or exceeds the permitted use, you will need to obtain permission directly from the copyright holder. To view a copy of this licence, visit http://creativecommons.org/licenses/by/4.0/ The Creative Commons Public Domain Dedication waiver (http://creativecommons.org/publicdomain/zero/1.0/) applies to the data made available in this article, unless otherwise stated in a credit line to the data. 
Conclusion: The results suggest that the quality of non-physician anesthetists' education has improved. Stagnation in competence scores of some stations and student perceptions of the simulated learning environment require specific attention.

Keywords: Anesthesia, Non-physician anesthetists, Ethiopia, Education quality, Objective structured clinical examination, Competence

\section{Background}

Globally, health systems have undergone extensive changes over the past three decades. Promising opportunities are emerging while many barriers remain, particularly in low- and middle-income countries (LMIC). The number of health facilities with essential infrastructure has generally shown improvement along with the health workforce density. Key health outcome indicators including infant, under-five, and maternal mortality rates have all declined significantly worldwide. However, improvements are not uniform across nations, and LMICs continue to report higher mortality rates and a critical shortage of skilled health workforce [1]. In LMICs, morbidity, and mortality as a result of treatable surgical conditions have increased sharply while at the same time efforts made to improve access to safe and essential lifesaving surgical and anesthetic care have stagnated. In LMICs an additional 143 million surgeries are required each year to save lives and prevent disability [2]. The Lancet Commission on Global Surgery estimates that, in Ethiopia alone, at least five million surgical procedures should be performed every year to meet population needs [3]. However, no more than 38,000 surgeries took place in 2012- less than $1 \%$ of the estimated need $[4,5]$.

While there is one physician anesthesia provider per 4000-5000 people in high-income countries, there is less than one provider per one million people in Ethiopia [6]. Such a critical shortage of the anesthesia workforce coupled with limited training capacity, varying training standards, and uneven distribution hinders efforts made by LMICs to ensure access to safe anesthetic care $[6,7]$. The 2015-2020 health sector strategic plan made an unprecedented move by highlighting safe surgery and anesthesia as a priority area [8], responding to the World Health Assembly Resolution 68.15 on strengthening surgical and anesthetic care as part of ensuring Universal Health Coverage [9].

Given the critical shortage of physician anesthesia providers in the country, the Government of Ethiopia (GOE) scaled up anesthesia providers through a task-sharing that allowed non-physician clinicians to provide anesthetic services formerly reserved for medical specialists $[8,10,11]$. This workforce production was made possible through a rapid expansion of teaching institutions for non-physician anesthesia providers (also known as non-physician anesthetists) over seven years (2013-2020). As a result, non- physician anesthetists (NPAs) have become the predominant anesthesia service providers in Ethiopia and most east African countries $[6,8,11,12]$. Despite reasonably similar clinical anesthesia roles, the training models for NPAs are heterogeneous in Ethiopia and across the LMICs in terms of their entry requirements, length of training, and qualifications awarded. In the African continent alone, there are about 22 different types of training models for NPAs across 51 countries $[6,13-15]$. The entry requirements for these NPA training models were clinical nursing, other clinical experience, or high school completion in order of frequency. Diplomas and certificates were the widely awarded qualifications, followed by bachelor's and master's degrees with varying training durations from 9 months to 4 years depending on entry requirements and qualification awarded [13].

The Ethiopian training models for NPAs were originally designed to produce independent practitioners who can provide safe anesthetic care for essential and emergency surgical interventions. These models include a year of training for nurses (known as level-V anesthetic nursing), a 3-year baccalaureate training of nurses, a 4year baccalaureate training program for high school graduates, and a 2-year post-baccalaureate master's degree training $[13,16]$. These models were carefully designed to allow career advancement of practitioners from the lowest level (Level-V anesthetic nursing), which is tasked to provide anesthetic care for the bellwether procedures to the baccalaureate and the master levels who relatively have broader practice scopes. The current Ethiopian strategic plan for surgery mainly focuses on the bellwether procedures (defined as cesarean section, laparotomy, and open fracture management) and few selected specialty services.

Improving anesthetic and surgical training and practice standards can contribute to at least nine of the 13 SDG3 targets directly or indirectly $[17,18]$. Thus, it is imperative to periodically evaluate quality of anesthesia education by selecting suitable evaluation designs, like experimental and quasi-experimental studies [19]. By defining input, process and outcome parameters that quantify the main elements of an educational system, evaluation designs can be employed to assess changes in the quality of education [20]. In the medical education literature, input refers to the resources and infrastructure needed to run programs, while process refers to educational activities, and outcome 
embraces the measure of competence [21, 22]. However, evaluation data on the quality of training for the nonphysician clinicians are scarce and marred with methodological limitations.

A 2013 baseline study conducted in Ethiopia showed significant gaps in the quality of NPA's education [23]. The current study evaluated effects of program interventions by the GOE, the USAID Human Resources for Health (HRH) Project and other development partners. The primary study objective was to evaluate changes in the competence of graduating NPAs in 2016 students compared to the level in 2013. The secondary objective was to assess improvements in the learning environment over the three years.

\section{Methods}

\section{Study design}

Considering the complexity of health professionals' education environment for tightly controlled designs with randomization, we opted for a quasi-experimental design [19]. To assess the impact of program interventions on quality of education we applied a pre-post evaluation design without control, implying data collection among different groups of learners who passed similar training programs [24]. Changes in competence of graduating NPAs and the learning environment from the baseline level were used as indicators to evaluate the quality of anesthesia education.

\section{Study population and setting}

The study population was the graduating class NPAs in 4 public universities and 2 regional health science colleges (RHSCs). We decided to recruit all graduating class NPA students available at the time of the study. Participants from universities completed a baccalaureate degree program (clinical nurses and high school graduates) while those from RHSCs were clinical nurses with a year of additional training in anesthesia (level $\mathrm{V}$ anesthetic nurses). The two group study participants at the different institutions were following the same nationally harmonized curricula.

\section{Sample size and sample selection procedure}

The evaluation employed a census at baseline and endline. All graduating students were invited to participate during the baseline $(n=200)$ and endline $(n=191)$ studies.

\section{Program interventions}

The Lancet Commission on Global Surgery recommended investment in strengthening training and professional development to increase the availability and accessibility of anesthesia providers in LMICs [2]. The USAID HRH Project (2012-2019) supported efforts of the Government of Ethiopia to increase the availability and quality of NPAs and other health workers. Project interventions (Table 1) were designed based on the Preservice Education conceptual model developed by Johnson et al. [25]. The key intervention approaches were:

- Building the capacity of anesthesia faculty to enhance teaching and assessment skills;

- Strengthening curricula to ensure core competencies are clearly defined, measured, and attained;

- Strengthening clinical education to increase the development of core professional competencies;

- Improving student support system to improve retention and performance;

- Enhancing school infrastructure to create an enabling environment for learning;

- Strengthening quality improvement and regulatory systems; and

- Increasing engagement and capacity of local professional associations to maximize sustainability.

\section{Measures and instruments}

Student competence was measured using a 10-station Objective Structured Clinical Examination (OSCE), a reliable and widely used method to assess clinical skills [26-29]. The stations were designed by trained subject matter experts to address core competencies required for the provision of safe anesthetic care for essential surgeries as identified by the World Bank [30]. To further ensure the content validity in the Ethiopian context, experts referred to local training curricula and crafted representative case scenarios and assessment rubrics encompassing the different competency domains. Eight of these stations were directly observed by a qualified assessor assigned to each station who exclusively used standardized objective checklists to rate performance. These stations covered [1] lumbar puncture [2]; neonatal resuscitation [3]; endotracheal intubation [4]; laryngeal mask airway insertion [5]; cardiopulmonary resuscitation [6]; chest examination [7]; preoperative screening assessment; and [8] routine anesthesia machine check. The remaining two stations required examinees to write down their answers and were later scored by assessors. These stations covered [1] interpreting postoperative complications; and [2] blood transfusion. Because of lack of mannequins and relevant educational resources, three stations (lumbar puncture, neonatal resuscitation, and anesthesia machine check) were unobservable in two of the study sites at baseline and improvised to an oral question. Scoring rubrics consisted of 5 to 16 items/ steps that aimed to measure clinical decision making, communication, and psychomotor skills. Competence 
Table 1 Program interventions implemented between 2013 and 2016

\begin{tabular}{|c|c|c|}
\hline Area & Elements of the program intervention & Timeline \\
\hline $\begin{array}{l}\text { Faculty } \\
\text { Development }\end{array}$ & $\begin{array}{l}\text { - Designed and delivered series of needs-based training for a total of } 1434 \text { anesthesia tutors \& preceptors (double- } \\
\text { counting might exist) } \\
\text { - Training areas included teaching methods (effective teaching skills, simulation-based training, problem-based learn- } \\
\text { ing, student assessment, instructional design skills) and technical updates on a variety of health topics }\end{array}$ & $\begin{array}{l}\text { Since } \\
2013\end{array}$ \\
\hline $\begin{array}{l}\text { Curricula } \\
\text { strengthening }\end{array}$ & $\begin{array}{l}\text { - Developed four competency-based national curricula (Level V, post-basic BSc, generic BSc and MSc anesthesia } \\
\text { programs) } \\
\text { - Objective Structured Clinical Examination (OSCE) and workplace-based assessments introduced }\end{array}$ & $\begin{array}{l}\text { Since } \\
2013\end{array}$ \\
\hline Clinical education & $\begin{array}{l}\text { - Strengthened clinical practice sites with over } 20 \text { clinical management algorithms and } 13 \text { universal anesthesia } \\
\text { machines integrated with patient monitors } \\
\text { - Donated } 13 \text { shuttle buses to facilitate clinical teaching }\end{array}$ & $\begin{array}{l}\text { Since } \\
2014\end{array}$ \\
\hline $\begin{array}{l}\text { Student support } \\
\text { system }\end{array}$ & $\begin{array}{l}\text { - Gender awareness improved and gender-responsive learning strengthened } \\
\text { - Targeted and informed student selection and recruitment of female students strengthened } \\
\text { - Orientation and psychosocial counseling services provided } \\
\text { - Life skills training, tutorial classes and financial support provided to female students and other students with } \\
\text { particular needs as identified by the respective teaching institution }\end{array}$ & $\begin{array}{l}\text { Since } \\
2013\end{array}$ \\
\hline Infrastructure & $\begin{array}{l}\text { - Equipped skills development labs with } 513 \text { simulators } \\
\text { - Stocked medical libraries with } 1174 \text { anesthesia books and } 8260 \text { common books } \\
\text { - Supported the development and printing of } 2405 \text { Level V anesthesia training modules ( } 13 \text { types) } \\
\text { - Distributed electronic ICT resources, such as } 12 \text { laptops, } 405 \text { desktop computers and } 24 \text { LCD projectors. }\end{array}$ & $\begin{array}{l}\text { Since } \\
2014\end{array}$ \\
\hline Regulation & $\begin{array}{l}\text { - Introduced national licensing examination } \\
\text { - Developed and supported the use of educational standards for self-review and accreditation purposes } \\
\text { - Developed code of ethics and conduct and scopes of practice for NPAs Developed nine continuing professional } \\
\text { development (CPD) training packages }\end{array}$ & $\begin{array}{l}\text { Since } \\
2014\end{array}$ \\
\hline Sustainability & $\begin{array}{l}\text { - Built leadership, strategic planning and management capabilities of the Ethiopian Association of Anesthetists (EAA) } \\
\text { - Opened and furnished an office with a CPD unit } \\
\text { - Purchased and donated a vehicle } \\
\text { - Increased membership from } 230 \text { to } 2150\end{array}$ & $\begin{array}{l}\text { Since } \\
2013\end{array}$ \\
\hline
\end{tabular}

assessments were performed voluntarily for study purposes only.

To measure quality of the learning environment (inputs and processes) for the desired purpose, structured interviews were conducted with students. The interview consisted of 12 questions designed in line with the national educational program standard and the response options were 'Yes', 'Partially' or 'No' [31]. Furthermore, students were asked about the number of endotracheal intubations they performed during their study.

\section{Data collection}

The assessment was administered by trained senior anesthesia instructors (12 at baseline and 16 at endline) who had experience with skills assessments. Assessors, both baseline and endline, received a 3-day training including role-plays and discussion of ethical issues a week immediately before the data collection schedule. Over half of the assessors recruited for the endline study had also participated in the baseline assessment. Those who participated in the baseline study assessed similar stations at the endline. Assessors were not assigned to institutions they served as teaching staff to reduce bias. Baseline data were collected in June and July 2013, while the endline assessments were done from June to September 2016.
Assessors first administered structured face-to-face interviews to collect data on sociodemographic characteristics and the number of endotracheal intubations performed during training, followed by posing 12 questions on their perceptions of the learning environment. Intubation is an index procedure monitored in the national NPAs' curricula. Then the OSCE was administered. Students rotated through every OSCE station, read a case scenario and performed a task or responded to a question. Assessors observed the performance of each student to determine the successful conduct of each step listed in the observation checklist for that OSCE station. Ten minutes were allotted for a student to complete the task at each station. Overall data collection was overseen by trained supervisors.

\section{Data analysis}

Data entry and cleaning were performed using CSPro 5.0 and analyzed in STATA 14. The normal distribution assumptions together with outlier, linearity, multicollinearity and homoscedasticity were checked before data analysis. Competence score was computed by calculating the percentage of steps that students performed satisfactorily at each OSCE station. Stations had equal weight and the mean of the 10 stations was calculated to determine overall competence score. An independent sample t-test was used to compare competence between 
baseline and endline. The percentage of students who replied "yes" to statements in the structured interview was calculated to indicate a positive perception of the learning environment. Those who replied "partly" were recoded as "no", as the partial response is more likely to refer to a gap in the adequacy of the learning environment. The percentage of students who performed at least 200 endotracheal intubations was also calculated to check the attainment of the benchmark required in the Ethiopian curriculum. Also, the Odds ratios were computed using chi-square analysis to compare changes in perception of learning environment. A $p$-value of less than 0.05 was considered statistically significant for all tests.

\section{Ethical considerations}

Ethical approval for the study was obtained from the Johns Hopkins Bloomberg School of Public Health Institutional Review Board (IRB \#5051). Permission to conduct the study was also obtained from the Ministry of Health (MOH) and deans of training institutions. Informed oral consent was obtained from all study participants, and measures were taken to protect autonomy and data confidentiality.

\section{Results}

\section{Characteristics of students}

At baseline and endline, 122 and 104 graduating class students participated, respectively, which accounted for $61 \%(122 / 200)$ and $54.5 \%(104 / 191)$ of eligible students.
University students were predominantly males and younger whereas college students were largely females and older. However, there were no statistically significant differences in sex, age, entry behavior or previous anesthesia-related job experience between baseline and endline study groups (Table 2).

\section{Changes in competence scores of students}

The mean score across all 10 OSCE stations revealed that the competence of students significantly increased by more than four percentage points from the baseline (65.7\% vs. $61.5,95 \% \mathrm{CI}=1.25-7.22, p<0.05)$. Lumbar puncture for spinal anesthesia was the skill in which students scored the highest at endline (79.6\%), followed by endotracheal intubation (76.9\%). OSCE stations with the lowest competence scores at baseline showed a significant improvement at endline (Fig. 1).

As shown in Table 3, university students outperformed RHSC students at both baseline and endline, though the gap had widened from $9.0 \%$ at baseline to $18.6 \%$ at endline. University students scored significantly higher at endline than at baseline in three OSCE stations. On the contrary, students from universities scored significantly lower in laryngeal mask airway insertion at endline than at baseline $(81.8 \%$ vs. $74.6 \%$, mean score difference $=$ $-7.2,95 \% \mathrm{CI}=-12.7$ to $-1.7, p<0.05)$. Students from RHSCs had significantly lower scores in performing a lumbar puncture, neonatal resuscitation, and chest examination at endline compared to the baseline.

Table 2 Comparison of non-physician anesthesia students' sociodemographic characteristics, baseline (2013) and endline (2016)

\begin{tabular}{|c|c|c|c|c|c|c|}
\hline \multirow[t]{2}{*}{ Variable } & \multicolumn{2}{|l|}{ University } & \multirow[t]{2}{*}{$P$-value } & \multicolumn{2}{|l|}{ RHSC } & \multirow{2}{*}{$\begin{array}{l}P \text { - } \\
\text { value }\end{array}$} \\
\hline & Baseline $(n=81)$ & Endline (=87) & & Baseline $(n=41)$ & Endline $(n=17)$ & \\
\hline \multicolumn{7}{|l|}{ Gender } \\
\hline Male & 69.1 & 57.47 & 0.117 & 21.95 & 23.53 & 0.574 \\
\hline Female & 30.9 & 42.53 & & 78.05 & 76.47 & \\
\hline \multicolumn{7}{|l|}{ Age in years } \\
\hline $20-24$ & 88.9 & 96.55 & 0.051 & 17.07 & 29.41 & 0.510 \\
\hline $25-30$ & 11.1 & 3.45 & & 70.73 & 58.82 & \\
\hline$>=30$ & 0 & 0 & & 12.2 & 11.76 & \\
\hline \multicolumn{7}{|l|}{ Hometown } \\
\hline Urban & 64.2 & 13.79 & $<0.001^{*}$ & 58.54 & 35.29 & 0.107 \\
\hline Rural & 35.8 & 86.21 & & 41.46 & 64.71 & \\
\hline \multicolumn{7}{|c|}{ Previous job experience related to anesthesia } \\
\hline Yes & 4.9 & 4.7 & 0.606 & 4.88 & 17.65 & 0.144 \\
\hline No & 95.1 & 95.4 & & 95.12 & 82.35 & \\
\hline \multicolumn{7}{|l|}{ Entry behavior } \\
\hline High school graduates & 82.7 & 80.5 & 0.706 & 0 & 0 & $-{ }^{a}$ \\
\hline Clinical nurses & 17.3 & 19.5 & & 100 & 100 & \\
\hline
\end{tabular}

Note: Abbreviation: RHSC, regional health science college

$P$ values were calculated using the Pearson chi-square test. ${ }^{*}$ indicates $P$ values considered statistically significant at $<0.05 .{ }^{a}$ indicates no staistics are computed because entry behavioue is constant 


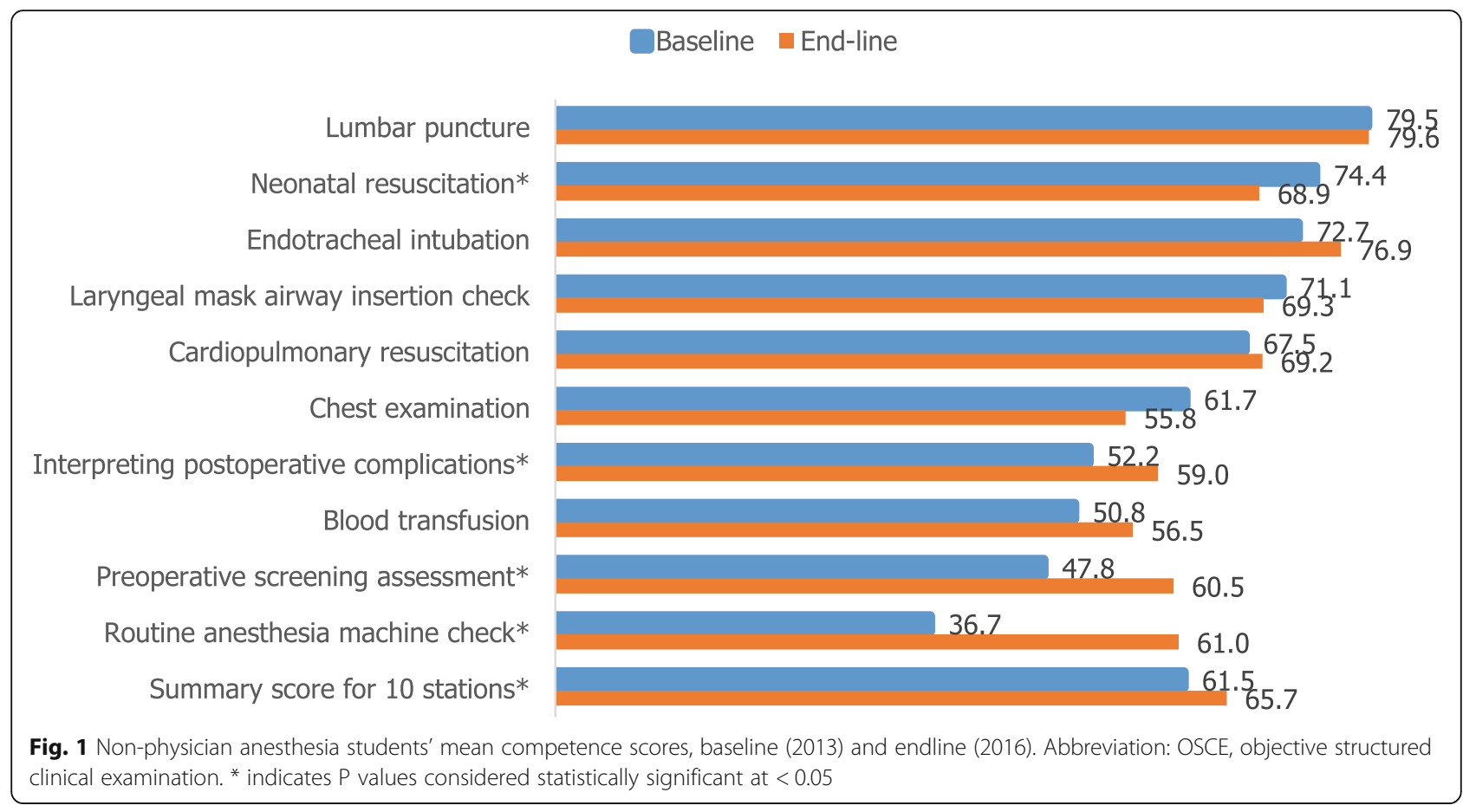

Gender gaps in competence scores observed at baseline in favor of males $(56.9 \%$ vs. $63.3 \%$, mean score difference $=6.4,95 \% \mathrm{CI}=2.6-10.0, p>0.05)$ disappeared in the endline $(66.3 \% \mathrm{vs} .65 .3 \%$, mean score difference $=$ $-1.0,95 \% \mathrm{CI}=-6.11-3.9, p>0.05)$ (Data not shown).

\section{Students' perceptions of the learning environment}

Student perceptions of educational inputs and processes improved significantly from baseline for 11 of the 12 items studied, with the largest percentage point increase in the availability of instructors from 38.5 to $70.2 \%$ $(\mathrm{OR}=3.76,95 \% \mathrm{CI}=2.15-6.55, p<0.05)$. Significant improvement was observed in almost all items at universities with the largest gain in the availability of instructors from 46.9 to $78.2 \%(\mathrm{OR}=4.05,95 \% \mathrm{CI}=$ 2.07-7.92, $p<0.05)($ Table 4).

Number of endotracheal intubations performed by students The number of endotracheal intubations performed by the students during their training ranged widely both at

Table 3 Percentage change in the competence scores of non-physician anesthesia students from baseline (2013) to endline (2016), by institution type

\begin{tabular}{|c|c|c|c|c|c|c|}
\hline \multirow[t]{2}{*}{ OSCE station } & \multicolumn{3}{|c|}{ University } & \multicolumn{3}{|l|}{ RHSC } \\
\hline & $\begin{array}{l}\text { Baseline } \\
(n=81)\end{array}$ & $\begin{array}{l}\text { Endline } \\
(n=87)\end{array}$ & $\begin{array}{l}\text { Mean score } \\
\text { difference }[95 \% \mathrm{Cl}]\end{array}$ & $\begin{array}{l}\text { Baseline } \\
(n=41)\end{array}$ & $\begin{array}{l}\text { Endline } \\
(n=17)\end{array}$ & $\begin{array}{l}\text { Mean score } \\
\text { difference }[95 \% \mathrm{Cl}]\end{array}$ \\
\hline Lumbar puncture & 78.9 & 82.8 & $+3.9[-0.1,8.7]$ & 80.7 & 63.5 & $-17.2[-31.4,-3.0]^{*}$ \\
\hline Neonatal resuscitation & 75.3 & 72.2 & $-3.1[-8.5,2.3]$ & 72.7 & 52.4 & $-20.3[-32.9,-7.8]^{*}$ \\
\hline Endotracheal intubation & 71.0 & 78.3 & $+7.3[2.1,12.6]^{*}$ & 76.2 & 69.5 & $-6.7[-18.0,4.6]$ \\
\hline Laryngeal mask airway insertion check & 81.8 & 74.6 & $-7.2[-12.7,-1.7]^{*}$ & 50.1 & 42.5 & $-7.6[-27.1,11.8]$ \\
\hline Cardiopulmonary resuscitation & 66.3 & 70.2 & $+3.9[-2.7,10.5]$ & 69.8 & 64.2 & $-5.6[-18.5,7.2]$ \\
\hline Chest examination & 65.2 & 59.2 & $-6.0[-13.0,0.09]$ & 54.7 & 38.7 & $-16.0[-27.9,-4.0]^{*}$ \\
\hline Interpreting postoperative complications & 55.6 & 60.9 & $+5.3[-0.1,10.9]$ & 45.5 & 49.4 & $+3.9[-8.3,16.1]$ \\
\hline Blood transfusion & 58.8 & 59.1 & $+0.3[-5.6,6.1]$ & 35.1 & 43.4 & $+8.3[-4.1,20.7]$ \\
\hline Preoperative screening assessment & 50.6 & 63.9 & $+13.3[8.0,18.5]^{*}$ & 42.3 & 43.1 & $+0.8[-9.0,10.7]$ \\
\hline Routine anesthesia machine check & 41.4 & 66.2 & $+24.8[18.3,31.4]^{*}$ & 27.4 & 34.3 & $+6.9[-1.4,15.2]$ \\
\hline Summary score for 10 stations & 64.5 & 68.7 & $+4.2[1.49,7.02]^{*}$ & 55.5 & 50.1 & $-5.4[-12.7,2.0]$ \\
\hline
\end{tabular}

Abbreviations: OSCE objective structured clinical examination, $R H S C$ regional health science college

* $P$ values considered statistically significant at $<0.05$ as calculated by the independent sample t-test 
Table 4 Percent changes in non-physician anesthesia students' perceptions of the learning environment from baseline (2013) to endline (2016), by training institution type

\begin{tabular}{|c|c|c|c|c|c|c|c|c|c|}
\hline \multirow[t]{2}{*}{ Conditions in facilities } & \multicolumn{3}{|l|}{ Overall } & \multicolumn{3}{|c|}{ University } & \multicolumn{3}{|l|}{ RHSC } \\
\hline & $\begin{array}{l}\text { Baseline } \\
(n=122)\end{array}$ & $\begin{array}{l}\text { Endline } \\
(n=104)\end{array}$ & $\begin{array}{l}\text { OR } \\
{[95 \% \mathrm{Cl}]}\end{array}$ & $\begin{array}{l}\text { Baseline } \\
(n=81)\end{array}$ & $\begin{array}{l}\text { Endline } \\
(n=87)\end{array}$ & $\begin{array}{l}\text { OR } \\
{[95 \% \mathrm{Cl}]}\end{array}$ & $\begin{array}{l}\text { Baseline } \\
(41)\end{array}$ & $\begin{array}{l}\text { Endline } \\
\text { (17) }\end{array}$ & $\begin{array}{l}\text { OR } \\
{[95 \% \mathrm{Cl}]}\end{array}$ \\
\hline \multicolumn{10}{|l|}{ Classroom } \\
\hline $\begin{array}{l}\text { Number of instructors is } \\
\text { adequate }\end{array}$ & 38.5 & 70.2 & $3.76[2.15,6.55]^{*}$ & 46.9 & 78.2 & $4.05[2.07,7.92]^{*}$ & 21.9 & 29.4 & $1.48[0.41,5.32]$ \\
\hline $\begin{array}{l}\text { Instructors are effective } \\
\text { in facilitating learning }\end{array}$ & 50.0 & 67.3 & $2.06[1.2,3.54]^{*}$ & 41.9 & 70.1 & $3.24[1.72,6.13]^{*}$ & 65.9 & 52.9 & $0.58[0.19,1.84]$ \\
\hline $\begin{array}{l}\text { Instructors are fair and } \\
\text { unbiased in assessing } \\
\text { learning }\end{array}$ & 48.4 & 71.0 & $2.3[1.33,3.96]^{*}$ & 34.6 & 64.4 & $3.42[1.81,6.45]^{*}$ & 75.6 & 88.2 & $2.42[0.47,12.45]$ \\
\hline $\begin{array}{l}\text { Classroom resources are } \\
\text { available and helpful }\end{array}$ & 26.2 & 47.1 & $2.51[1.44,4.38]^{*}$ & 27.2 & 47.1 & $2.39[1.25,4.56]^{*}$ & 24.4 & 47.1 & $2.76[0.84,9.05]^{*}$ \\
\hline \multicolumn{10}{|l|}{ Skills lab } \\
\hline $\begin{array}{l}\text { Number of skills lab } \\
\text { assistants is adequate }\end{array}$ & 4.9 & 21.4 & $5.25[2.04,13.53]^{*}$ & 2.5 & 25.6 & $13.58[3.07,59.9]^{*}$ & 9.8 & 0.0 & $0.02^{\mathrm{a} *}$ \\
\hline $\begin{array}{l}\text { Skills lab assistants } \\
\text { effectively support } \\
\text { students }\end{array}$ & 9.0 & 33.7 & $5.12[2.44,10.74]^{*}$ & 6.2 & 35.6 & $8.4[3.08,23.0]^{*}$ & 14.6 & 23.5 & $1.8[0.44,7.4]$ \\
\hline $\begin{array}{l}\text { Skills lab resources are } \\
\text { available and helpful }\end{array}$ & 9.0 & 34.6 & $5.34[2.55,11.19]^{*}$ & 8.6 & 39.1 & $6.78[2.79,16.46]^{*}$ & 9.8 & 11.8 & $1.23[0.2,7.46]^{*}$ \\
\hline \multicolumn{10}{|l|}{ Clinical practice sites } \\
\hline $\begin{array}{l}\text { Clinical practice sites are } \\
\text { conducive to learning }\end{array}$ & 38.5 & 56.7 & $2.19[1.28,3.74]^{*}$ & 37.0 & 58.8 & $2.43[1.3,4.54]^{*}$ & 41.7 & 52.9 & $1.59[0.51,4.95]$ \\
\hline $\begin{array}{l}\text { Practical experience is } \\
\text { sufficient }\end{array}$ & 55.7 & 64.4 & $1.44[0.84,2.46]$ & 58.0 & 69.0 & $1.61[0.85,3.03]$ & 51.2 & 41.1 & $0.67[0.21,2.09]$ \\
\hline $\begin{array}{l}\text { Preceptors are present at } \\
\text { practicum sites }\end{array}$ & 72.1 & 91.3 & $4.08[1.85,8.99]^{*}$ & 62.9 & 90.8 & $5.81[2.47,13.67]^{*}$ & 90.2 & 94.1 & $1.73[0.18,16.72]$ \\
\hline \multicolumn{10}{|c|}{ Among students who said that preceptors were present at practicum sites: } \\
\hline $\begin{array}{l}\text { Number of preceptors is } \\
\text { adequate }\end{array}$ & 25.4 & 45.2 & $1.73[0.96,3.14]^{*}$ & 31.4 & 55.0 & $2.67[1.28,5.59]^{*}$ & 41.7 & 18.8 & $0.32[0.08,1.33]$ \\
\hline $\begin{array}{l}\text { Preceptors are available } \\
\text { at scheduled times and } \\
\text { support students }\end{array}$ & 33.6 & 55.8 & $1.68[0.93,3.02]^{*}$ & 38.0 & 58.8 & $2.25[1.09,4.65]^{*}$ & 59.5 & 68.8 & $1.5[0.43,5.21]$ \\
\hline
\end{tabular}

Abbreviation: $R H S C$ regional health science college

* indicates $P$ values considered statistically significant at $<0.05$ by using the Pearson chi-square test

${ }^{a}$ indicates a $P$ value calculated using Fisher's Exact Test as more than $25 \%$ of the cells have $<5$ observation

baseline (20-601) and endline (28-350). While the overall median was 200 at both baseline and endline, university students performed more intubations than RHSC students at both baseline (220 vs. 95 ) and endline (200 vs. 65) (Data not shown).

\section{Discussion}

Access to safe and affordable surgery depends partly on scaling up essential workforce density, addressing the critical shortage of human resources that has hampered service delivery to more than 5 billion people $[2,10,32]$. Task sharing is one of the most widely strategies used by LMICs to address the human resource gap [10, 32]. By expanding training of NPAs, the Ethiopian Government increased the anesthesia workforce density by more than fourfold - from 1 per 333,000 populations in 2012 [33] to 1 per 69,470 in 2019 [34]. However, resilient surgical and anesthetic care cannot be envisioned without addressing quality and safety concerns [18]. Particularly, when implementing task sharing, it is critical to maintain service quality and safety through human resource quality assurance mechanisms in areas of training and service provision [35-37].

A study we conducted in 2013 had documented large gaps in quality of non-physician anesthesia education [23]. The Government of Ethiopia implemented interventions to improve quality of education of health professionals. Thus, the objective of this study was to evaluate improvement in quality of anesthesia education. We found significant improvements not only in educational inputs and processes but also clinical competence of NPA students from the baseline. Considering the 
evaluation is carried out within a short period (1-3 years) after the interventions and during a time when the number and enrollment capacities of NPA teaching institutions are drastically increased, the observed improvement (especially in the university groups) is encouraging. However, the modest increment together with the stagnation or decline of some of the components assessed (e.g. neonatal resuscitation) raises concern about the preparation of these graduates to provide safe patient care. This could add fuel to the already increased anesthesia-related safety risk found in LMICs [18]. As data on the competence of NPAs is so scarce globally, comparison with similar studies was not possible. However, competence studies involving nurses [38, 39], midwives [40, 41], and other allied healthcare providers [42] across the LMICs have shown that acquiring sufficient competency levels is a global educational challenge.

With a positive shift in the university group, the overall improvement in the endotracheal intubation score in the OSCE $(72.7 \%$ vs. $76.9 \%)$ is a positive achievement given that airway management is the number one safety issue in anesthesia practice [43] and the inability to perform it correctly contributes to about two-thirds of reported anesthesia-related maternal deaths [44]. In this study, the improvement in the intubation score despite a decline in the number of endotracheal intubations can be explained by the increased use of skill development labs (mannequins) to practice the skill during training $[45,46]$.

Findings from the endline assessment revealed that the pre-existing gender-based performance differences had disappeared, and even female students scored better in some stations. Targeted and informed student recruitment, motivation, and socioeconomic support of female students combined with institutional gender-responsive learning might have played a role in improving the performance of female students. Such transformative approaches are recommended by the WHO to improve gender equity in education [47]. Ensuring gender equality in health workforce training is important to achieve not only SDG 5 (gender equality) and SDG 3 (health and wellbeing), but also others including SDG 4 (quality education) and SDG 8 (decent work and inclusive economic growth) [48]. Collectively, this will bring significant health, social, and economic benefits to society [47, 49-51].

Of concern, students from RHSCs fall behind their university counterparts at both baseline and endline, gap widened at endline. Given that RHSC graduates are assigned after graduation to provide anesthesia service in primary hospitals where there is little to no opportunity to seek on-the-job assistance, efforts should be strengthened to improve the quality of this training. Critical faculty shortage, inadequate teaching facilities, and insufficient clinical practice opportunities to master core competencies may have contributed to the dismal finding. Increasing the use of simulation-based teaching, early clinical exposure, cognitive apprenticeship, and twining with nearby universities for shared resource utilization can be considered to address the competence gaps. Since this study did not explore other potential determinants of academic performance including high school grades and training duration, the recommendations have limitations.

The learning environment can have a lasting impact on the knowledge, critical reasoning, and motivation of the students. It serves as a key indicator for evaluating the curriculum and learning experiences of students where their satisfaction indicates the quality of an educational program [52-55]. This study revealed a significant improvement in the learning environment for almost all items studied, with the largest percentage point increases in the availability and effectiveness of instructors. This might be attributable to the government's increased emphasis on availing a standard number of instructors along with the faculty development interventions implemented by the project. Besides, it is worth noting the efforts made by the project to strengthen the NPA MSc program may have improved availability of qualified instructors. However, the inadequate skill labs, limited classroom facilities, and poorly managed clinical practice were the persistent areas of concern. This finding calls for a wide-range of improvements including increasing the availability of teachers, skills lab assistants and clinical preceptors; increasing investment in learning environments, especially simulation-based teaching; implementing need-based faculty development programs; standardizing clinical learning; and enhancing public-private partnerships.

In summary, this study pointed out that task-sharing can be effectively employed to produce competent nonphysicians who can provide clinical services originally designated for specialists. However, a well-delineated scope of practice that puts a delicate balance between access and quality of care is fundamental. Such a practice regulation is vital in preventing task-sharing that might result in uncontrolled and risky role modifications. The roles for different levels of practitioners should be set based on priority tasks, complexity and risk of procedures, and learning curve [10]. The learning curve can be enhanced by designing, implementing, and regulating need-based training. In this regard, education quality assurance, licensing, and accreditation systems are worth considering to standardize the quality of training nationally and regionally. Task-sharing shouldn't be only seen as a short-term solution to fix specialist shortages, rather a sustainable and long-term approach that focuses on producing a workforce resilient to burnout and other professional challenges [36, 56-58]. 
Furthermore, it shouldn't be late to pause and reflect on the different NPAs training models and establish an agreed-upon standardization framework.

\section{Strength and limitations}

There are a range of strengths to this evaluation study. First, it covered all non-physician anesthesia training institutions to get nationally representative samples. Second, data were collected before and after an intervention, allowing evaluation of change in education quality between the two-time points. Third, multiple quality indicators were evaluated in the causal chain of educational inputs, processes, outputs, and outcome, providing a chance for triangulation. Finally, student performance was assessed using OSCE, which is the preferred method because of its high objectivity and reliability even in national licensing exams.

The most important limitations of this study are the lack of randomization and a control group. As a result, the evaluation design employed in this study might not distinguish the direct effects of the program interventions from any other effect due to external factors to the program [24, 59]. However, the authors have not identified and discovered any variations in program-related characteristics between the two groups. In this study, though assessors received extensive prior training to reduce variations in OSCE scoring, differences for interobserver ratings cannot be avoided completely. This study didn't compute inter-rater reliability to make comparisons between the baseline and endline groups. Two RHSCs assessed at the baseline were not part of the endline assessment since they did not have graduate class students during data collection. Thus, they were replaced by two others with similar characteristics. Finally, 78 students during baseline and 87 during endline did not participate in the study as they were not found on campus during data collection. Furthermore, variations in the performance scoring of three stations (lumbar puncture, neonatal resuscitation, and anesthesia machine check) at two sites (oral questioning during baseline vs. direct performance observation during the endline) might have contributed to the difference.

\section{Conclusion}

The results of this study showed that the causal chain of educational inputs, processes, outputs, and outcomes have improved significantly since 2013, indicating better education quality of NPAs. Nonetheless, there were still considerable gaps suggesting the need to do more for greater and accelerated impact. Gaps include lack of progress in the competence of RHSC students, low absolute competence scores, and inadequate improvements in the learning environment in RHSCs.
Given that all students who participated in the study have joined the workforce, the study authors recommend that the Federal Ministry of Health and partners implement performance improvement measures such as on the job/ in-service training, mentoring, supportive supervision, audit, and feedback to enhance the skill of new graduates. Competencies with the lowest scores warrant examination of curricula and scopes of practice. Interventions at the pre-service education level shall focus on key challenges through innovative approaches, including the maximal use of educational technologies and digital learning.

While this study broke new ground in Ethiopia, it has important research implications as well. Future pre-post design evaluation studies should attempt to include a control group with an interrupted time-series design to better establish a relationship between cause and effect. The authors also recommend a mixed-methods study involving not only students but also teachers and academic leaders to support arguments that particular intervention can be related to the improvements in education quality.

\section{Abbreviations}

GOE: Government of Ethiopia; NPAP: Non-physician Anesthesia Providers: NPA: Non-physician Anesthetist; OSCE: Objective Structured Clinical Examination; RHSC: Regional Health Science College

\section{Acknowledgments}

The study authors would like to thank the Federal Ministry of Health, Regional Health Bureaus, Ethiopian Association of Anesthetists, and study site teaching institutions for their support and inputs. The authors would like to express special appreciation to Tadesse Belayneh from the University of Gondar and Abebaw Demissie from Harar Health Science college for their involvement in drafting a study technical report.

\section{Authors' contributions}

YMA, TY, and FAD conceptualized the study. YMA, TY, FAD, FS, and TA have all made significant contributions to the scientific content of this manuscript. YMA, TY, and FAD carried out data collection and analysis. YMA drafted the first manuscript. YMA, TY, FAD, FS, and TA critically reviewed and revised the manuscript. All the authors have read and approved the final manuscript.

\section{Authors' information}

YMA is an Ethiopian citizen and currently doing his PhD at Vrije Universiteit Amsterdam and attained a fellowship and postgraduate certificates in health professions education from FAIMER and Keele university respectively. TA, FS, and TY are the promotors for the corresponding author on his PhD study.

\section{Funding}

This study was made possible by the generous support of the American people through the United States Agency for International Development (USAID) under the Cooperative Agreement AID-663-A-12-00008. The contents are the responsibility of Jhpiego and do not necessarily reflect the views of USAID or the United States Government.

\section{Availability of data and materials}

The dataset that supports the analysis and interpretation of findings from the current study are available from the corresponding author on reasonable request.

\section{Declarations}

Ethics approval and consent to participate

Ethical approval for the study was obtained from the Johns Hopkins Bloomberg School of Public Health Institutional Review Board (IRB \#5051). 
Accordingly, the school's Responsible Conduct of Research was strictly followed as a governing guideline across the different phases of the study. Permission to conduct the study was also obtained from the Ethiopian Ministry of Health and deans of training institutions. Informed consent was obtained from all study participants, and measures were taken to protect autonomy and data confidentiality.

\section{Consent for publication}

Not applicable.

\section{Competing interests}

The authors declare that they have no competing interests.

\section{Author details}

${ }^{1}$ Jhpiego, An affiliate of Johns Hopkins University, Ethiopia country office, Addis Ababa, Ethiopia. ${ }^{2}$ Athena Institute for Transdisciplinary Research, Amsterdam, The Netherlands. ${ }^{3}$ OLVG Teaching Hospital, Amsterdam, The Netherlands. ${ }^{4}$ Amsterdam UMC, Amsterdam, the Netherlands. ${ }^{5}$ Dutch Royal Medical Council, Chair Legislative College for Accreditation of Residency Training 2016-2019, Utrecht, The Netherlands. ${ }^{6}$ Athena Institute, Faculty of Science, Vrije Universiteit Amsterdam, Amsterdam, The Netherlands. ${ }^{7}$ Department of Obstetrics and Gynaecology, Leiden University Medical Centre, Leiden, The Netherlands.

\section{Received: 30 March 2021 Accepted: 16 July 2021}

\section{Published online: 08 August 2021}

\section{References}

1. Durrani H. Healthcare and healthcare systems: inspiring progress and future prospects. Mhealth. 2016;2:3

2. Meara JG, Leather AJ, Hagander L, Alkire BC, Alonso N, Ameh EA, et al. Global surgery 2030: evidence and solutions for achieving health, welfare, and economic development. Lancet. 2015;386(9993):569-624. https://doi. org/10.1016/S0140-6736(15)60160-X.

3. Esquivel MM, Molina G, Uribe-Leitz T, Lipsitz SR, Rose J, Bickler S, et al. Proposed minimum rates of surgery to support desirable health outcomes: an observational study based on three strategies. World J Surg. 2015;39(9): 2126-31. https://doi.org/10.1007/s00268-015-3092-7.

4. Weiser TG, Haynes AB, Molina G, Lipsitz SR, Esquivel MM, Uribe-Leitz T, et al. Size and distribution of the global volume of surgery in 2012. Bull World Health Organ. 2016;94(3):201-9F. https://doi.org/10.2471/BLT.15.159293.

5. LeBrun DG, Chackungal S, Chao TE, Knowlton LM, Linden AF, Notrica MR, et al. Prioritizing essential surgery and safe anesthesia for the Post-2015 development agenda: operative capacities of 78 district hospitals in 7 lowand middle-income countries. Surgery. 2014;155(3):365-73. https://doi.org/1 0.1016/j.surg.2013.10.008.

6. Kempthorne P, Morriss WW, Mellin-Olsen J, Gore-Booth J. The WFSA global anesthesia workforce survey. Anesth Analg. 2017;125(3):981-90. https://doi. org/10.1213/ANE.0000000000002258.

7. Morriss W, Ottaway A, Milenovic M, Gore-Booth J, Haylock-Loor C, OnajinObembe B, et al. A global anesthesia training framework. Anesth Analg. 2019;128(2):383-7. https://doi.org/10.1213/ANE.0000000000003928.

8. Ethiopian Federal Ministry of Health. Health Sector Transformation Plan (2015/16-2019/20). 2015:183

9. Price R, Makasa E, Hollands M. World health assembly resolution WHA68. 15: "strengthening emergency and essential surgical care and anesthesia as a component of universal health coverage" —addressing the public health gaps arising from lack of safe, affordable and accessible surgical and anesthetic services. World J Surg. 2015;39(9):2115-25. https://doi.org/10.1 007/s00268-015-3153-y.

10. Ashengo T, Skeels A, Hurwitz EJ, Thuo E, Sanghvi H. Bridging the human resource gap in surgical and anesthesia care in low-resource countries: a review of the task sharing literature. Hum Resour Health. 2017;15(1):77 https://doi.org/10.1186/s12960-017-0248-6.

11. Ethiopian Federal Ministry of Health. National Human Resources for Health Strategic Plan for Ethiopia (2016-2025). 2016:183.

12. Epiu I, Tindimwebwa JVB, Mijumbi C, Chokwe TM, Lugazia E, Ndarugirire F, et al. Challenges of anesthesia in low-and middle-income countries: a crosssectional survey of access to safe obstetric anesthesia in East Africa. Anesth Analg. 2017;124(1):290-9. https://doi.org/10.1213/ANE.0000000000001690.
13. Law TJ, Bulamba F, Ochieng JP, Edgcombe H, Thwaites V, Hewitt-Smith A, et al. Anesthesia provider training and practice models: a survey of Africa. Anesth Analg. 2019;129(3):839-46. https://doi.org/10.1213/ANE. 0000000000004302

14. Edgcombe H, Baxter L, Kudsk-Iversen S. Training non-physician anaesthetists in sub-Saharan Africa: a qualitative investigation of providers' perspectives; 2019.

15. Lipnick MS, Bulamba F, Ttendo S, Gelb AW. The need for a global perspective on task-sharing in anesthesia. Anesth Analg. 2017;125(3):104952. https://doi.org/10.1213/ANE.0000000000001988.

16. Kibwana S, Teshome M, Molla Y, Carr C, Akalu L, van Roosmalen J, et al. Education, practice, and competency gaps of anesthetists in Ethiopia: task analysis. J Perianesthesia Nurs. 2018;33(4):426-35. https://doi.org/10.1016/j. jopan.2017.02.001

17. Desa U. Transforming our world: the 2030 agenda for sustainable development. United Nations. 2016

18. Vaughan KA, Johnson WD. Progress and challenges in global surgical and anaesthesia care and safety: proceedings of the SAFE-T summit 2018. Update in Anaesthesia. 2019;33.

19. Stufflebeam DL, Coryn CL. Evaluation theory, models, and applications: John Wiley \& Sons; 2014.

20. Donabedian A. The quality of care. How can it be assessed? Jama. 1988; 260(12):1743-8. https://doi.org/10.1001/jama.1988.03410120089033.

21. Schwarz MR, Wojtczak A. Global minimum essential requirements: a road towards competence-oriented medical education. Med Teach. 2002;24(2): 125-9. https://doi.org/10.1080/01421590220120740.

22. Burdick B, Karle H, Simon F, Gale R. Standards for medical education. FAIM ER-Keele Master's in health professions education: accreditation and assessment. Module 2, unit 2. London: FAIMER Centre for Distance Learning, CenMEDIC; 2019.

23. Kibwana S, Woldemariam D, Misganaw A, Teshome M, Akalu L, Kols A, et al. Preparing the health workforce in Ethiopia: a cross-sectional study of competence of anesthesia graduating students. Educ Health (Abingdon). 2016;29(1):3-9. https://doi.org/10.4103/1357-6283.178931.

24. Frye AW, Hemmer PA. Program evaluation models and related theories: AMEE guide no. 67. Med Teach. 2012;34(5):e288-99. https://doi.org/10.3109/ 0142159X.2012.668637.

25. Johnson P, Fogarty L, Fullerton J, Bluestone J, Drake M. An integrative review and evidence-based conceptual model of the essential components of pre-service education. Hum Resour Health. 2013;11(1):42. https://doi.org/1 0.1186/1478-4491-11-42.

26. Khan KZ, Ramachandran S, Gaunt K, Pushkar P. The objective structured clinical examination (OSCE): AMEE guide no. 81. Part I: an historical and theoretical perspective. Medical teacher. 2013;35(9):e1437-e46. https://doi. org/10.3109/0142159X.2013.818634.

27. Khan KZ, Gaunt K, Ramachandran S, Pushkar P. The objective structured clinical examination (OSCE): AMEE guide no. 81. Part II: organisation \& administration. Med Teach. 2013;35(9):e1447-63. https://doi.org/10.3109/ 0142159X.2013.818635.

28. Gormley G. Summative OSCEs in undergraduate medical education. Ulster Med J. 2011;80(3):127-32.

29. Shumway JM, Harden RM. AMEE guide no. 25: the assessment of learning outcomes for the competent and reflective physician. Med Teach. 2003; 25(6):569-84. https://doi.org/10.1080/0142159032000151907.

30. Debas H, Donkor P, Gawande A, Jamison D, Kruk M, Mock C. Essential Surgery: Disease Control Priorities. 1. 3rd ed. Washington: The International Bank for Reconstruction and Development / The World Bank; 2015.

31. Higher Education Relevance and Quality Agency. National Accreditation and Quality Improvement Standards for Anesthesia Degree Program. First ed. Addis Ababa: 2014:56.

32. Federspiel F, Mukhopadhyay S, Milsom PJ, Scott JW, Riesel JN, Meara JG. Global surgical, obstetric, and anesthetic task shifting: a systematic literature review. Surgery. 2018;164(3):553-8. https://doi.org/10.1016/j.surg.2018.04.024.

33. Firew A, Misganaw A, Yigzaw T, Kibwana S, W/Mariam D, Kachara S. Strengthening Human Resources for Health in Ethiopia, Baseline Survey Findings. Un-published 2013:99.

34. Ethiopian Federal Ministry of Health. Anesthesia workforce account. Unpublished government report. 2019.

35. Bharati SJ, Chowdhury T, Gupta N, Schaller B, Cappellani RB, Maguire D. Anaesthesia in underdeveloped world: present scenario and future challenges. Niger Med J. 2014;55(1):1-8. https://doi.org/10.4103/0300-1 652.128146 
36. Kudsk-Iversen S, Shamambo N, Bould MD. Strengthening the anesthesia workforce in low- and middle-income countries. Anesth Analg. 2018;126(4): 1291-7. https://doi.org/10.1213/ANE.0000000000002722.

37. Organization $\mathbf{W H}$. Task sharing to improve access to family planning: World Health Organization; 2017.

38. Bifftu BB, Dachew BA, Tadesse Tiruneh B, Mekonnen Kelkay M, Bayu NH. Perceived clinical competence among undergraduate nursing students in the university of Gondar and Bahir Dar university, Northwest Ethiopia: a cross-sectional institution based study. Advances in Nurs. 2016;2016:1-7. https://doi.org/10.1155/2016/9294673.

39. Faraji A, Karimi M, Azizi SM, Janatolmakan M, Khatony A. Evaluation of clinical competence and its related factors among ICU nurses in Kermanshah-Iran: a cross-sectional study. Int J nurs sci. 2019;6(4):421-5. https://doi.org/10.1016/j.ijnss.2019.09.007.

40. Goshu M, Godefay H, Bihonegn F, Ayalew F, Haileselassie D, Kebede A, et al. Assessing the competence of midwives to provide care during labor, childbirth and the immediate postpartum period - a cross sectional study in Tigray region. Ethiopia PLoS One. 2018;13(10):e0206414. https://doi.org/1 0.1371/journal.pone.0206414.

41. Yigzaw T, Ayalew F, Kim Y-M, Gelagay M, Dejene D, Gibson H, et al. How well does pre-service education prepare midwives for practice: competence assessment of midwifery students at the point of graduation in Ethiopia. BMC med edu. 2015;15(1):130. https://doi.org/10.1186/s12909-015-0410-6.

42. Feldacker C, Chicumbe S, Dgedge M, Augusto G, Cesar F, Robertson M, et al. Mid-level healthcare personnel training: an evaluation of the revised, nationally-standardized, pre-service curriculum for clinical officers in Mozambique. PLoS One. 2014;9(7):e102588. https://doi.org/10.1371/journal. pone.0102588.

43. Stoelting RK. APSF Survey Results Identify Safety Issues Priorities. Anesthesia Patient Safety Foundation. https://www.apsf.org/article/apsf-survey-resultsidentify-safety-issues-priorities/. Accessed 30 Jan 2020.

44. Sobhy S, Zamora J, Dharmarajah K, Arroyo-Manzano D, Wilson M, Navaratnarajah $\mathrm{R}$, et al. Anaesthesia-related maternal mortality in lowincome and middle-income countries: a systematic review and metaanalysis. Lancet Glob Health. 2016;4(5):e320-e7. https://doi.org/10.1016/ S2214-109X(16)30003-1.

45. Komasawa N, Berg BW. Simulation-based airway management training for anesthesiologists - a brief review of its essential role in skills training for clinical competency. J Educ Perioper Med. 2017;19(4):E612.

46. Grande B, Kolbe M, Biro P. Difficult airway management and training: simulation, communication, and feedback. Curr Opin Anaesthesiol. 2017; 30(6):743-7. https://doi.org/10.1097/ACO.0000000000000523.

47. Organization $\mathbf{W H}$. Delivered by women, led by men: a gender and equity analysis of the global health and social workforce. 2019.

48. UNDP. Sustainable Development Goals. https://www.undp.org/content/ undp/en/home/sustainable-development-goals/. Accessed 20 Jan 2020.

49. Shannon G, Jansen M, Williams K, Caceres C, Motta A, Odhiambo A, et al. Gender equality in science, medicine, and global health: where are we at and why does it matter? Lancet. 2019;393(10171):560-9. https://doi.org/10.1 016/S0140-6736(18)33135-0.

50. World Health Organization. Five-year action plan for health employment and inclusive economic growth (2017-2021). 2018.

51. World Health Organization. Final report of the expert group to the highlevel commission on health employment and economic growth. 2016.

52. Faroog $S$, Rehman $R$, Hussain M, Dias JM. Comparison of undergraduate educational environment in medical and nursing program using the DREEM tool. Nurse Educ Today. 2018;69:74-80. https://doi.org/10.1016/j.nedt.2018. 06.031.

53. Imanipour M, Sadooghiasl A, Ghiyasvandian S, Haghani H. Evaluating the educational environment of a nursing school by using the DREEM inventory. Global J Health Sci. 2015;7(4):211-6. https://doi.org/10.5539/gjhs. $v 7 n 4 p 211$.

54. Farajpour A, Raisolsadat SMA, S Moghadam S, Mostafavian Z. Perception of educational environment among undergraduate students of health disciplines in an Iranian university. Int J Med Educ. 2017;8:300-6. https://doi. org/10.5116/ijme.5977.7129.

55. Patil AA, Chaudhari VL. Students' perception of the educational environment in medical college: a study based on DREEM questionnaire. Korean J Med Educ. 2016;28(3):281-8. https://doi.org/10.3946/kjme.2016.32.
56. Rosseel P, Trelles M, Guilavogui S, Ford N, Chu K. Ten years of experience training non-physician anesthesia providers in Haiti. World J Surg. 2010; 34(3):453-8. https://doi.org/10.1007/s00268-009-0192-2.

57. Kols A, Kibwana S, Molla Y, Ayalew F, Teshome M, van Roosmalen J, et al. Factors predicting Ethiopian anesthetists' intention to leave their job. World J Surg. 2018:42(5):1262-9. https://doi.org/10.1007/s00268-017-4318-7.

58. Kibwana S, Yigzaw M, Molla Y, van Roosmalen J, Stekelenburg J. Job satisfaction among anesthetists in Ethiopia - a national cross-sectional study. Int J Health Plann Manag. 2018;33(4):e960-e70. https://doi.org/10.1 002/hpm.2573.

59. Norman $G R$, van der Vleuten $C P$, Newble DI. International handbook of research in medical education: Springer Science \& Business Media; 2002. https://doi.org/10.1007/978-94-010-0462-6.

\section{Publisher's Note}

Springer Nature remains neutral with regard to jurisdictional claims in published maps and institutional affiliations.
Ready to submit your research? Choose BMC and benefit from:

- fast, convenient online submission

- thorough peer review by experienced researchers in your field

- rapid publication on acceptance

- support for research data, including large and complex data types

- gold Open Access which fosters wider collaboration and increased citations

- maximum visibility for your research: over $100 \mathrm{M}$ website views per year

At BMC, research is always in progress.

Learn more biomedcentral.com/submissions 